\title{
GUÍA PRÁCTICA DEL VÉRTIGO POSICIONAL PAROXÍSTICO BENIGNO: LA COLABORACIÓN COMO CAMINO A LA MEJORA ASISTENCIAL
}

\section{Practical guideline for benign paroxysmal positional vertigo: collaboration as way to improve the assistance}

\author{
José Ignacio BENITO-OREJAS ${ }^{1}$; Ángel BATUECAS-CALETRÍO ${ }^{2}$ \\ ${ }^{1}$ Servicio de ORL. Hospital Clínico Universitario de Valladolid. Valladolid. España \\ ${ }^{2}$ Unidad de Otoneurología. Sefrvicio de ORL y PCF. Hospital Uninversitario de Salamanca. IBSAL. Salamanca. España \\ Correspondencia: abatuc@yahoo.es
}

Fecha de publicación: 18 de febrero de 2017

Fecha de publicación del fascículo: 1 de septiembre de 2017

\begin{abstract}
Conflicto de intereses: Los autores declaran no tener conflictos de intereses
Imágenes: Los autores declaran haber obtenido las imágenes con el permiso de los pacientes Política de derechos y autoarchivo: se permite el autoarchivo de la versión post-print (SHERPA/RoMEO) Licencia CC BY-NC-ND. Licencia Creative Commons Atribución-NoComercial-SinDerivar 4.0 Internacional Universidad de Salamanca. Su comercialización está sujeta al permiso del editor
\end{abstract}

El vértigo posicional paroxístico benigno (VPPB) es la laberintopatía más frecuente, con un diagnóstico y tratamiento efectivos en la mayoría de los casos, pero no exento de incertidumbres que invitan a la reflexión.

Robert Bárány nos refiere en 1921 [1] el primer paciente con VPPB, aunque son Dix y Hallpike quienes en 1952 [2], exponen las características de la enfermedad, incluida su maniobra de provocación. Desde entonces se han publicado más de 1500 artículos sobre el tema, que han conducido a un progresivo avance en la epidemiología, fisiopatología, clínica y tratamiento de este proceso. El Committee for the Classification of Vestibular Disorders of the Bárány Society describe, de acuerdo con otras sociedades médicas expertas en otoneurología, los aspectos clínicos del síndrome y reserva un apartado para los casos controvertidos.

El atractivo que supone la explicación fisiopatológica de esta enfermedad en sus diferentes formas, no deja de ser especulativa. La hipótesis de la canalitiasis (propuesta por Hall et al, en 1979) [3] y la cupulolitiasis (Schuknecht, 1969) [4] se basan en razonamientos empíricos a partir de modelos animales y matemáticos y no en evidencias patológicas directas.

Aunque generalmente de causa desconocida, es posible que este padecimiento se vea influido por la presencia de otras comorbilidades, además de por la edad y el sexo femenino. El nistagmo posicional paroxístico tan característico, constituye el elemento diagnóstico principal. Su dirección refleja las conocidas conexiones de los receptores ampulares con específicos músculos extraoculares. 
Pero hay hallazgos clínicos asociados con el VPPB de difícil comprensión, como la presencia de un nistagmo espontáneo, ¿secundario a un bloqueo del canal o del flujo endolinfático?; o la de un nistagmo geotrópico persistente de dirección cambiante en posición supina y lateral de la cabeza, donde tras descartar una afectación central, ¿pudiera deberse a cambios en la densidad de la cúpula o de la endolinfa? También resulta complicado explicar el "VPPB subjetivo o posible», al tratarse de un vértigo posicional sin nistagmo; o el VPPB con nistagmo vertical inferior puro.

En 1992, Epley [5] publica su maniobra de reposición de partículas, explicando cómo se puede desplazar a las otoconias desde el conducto semicircular posterior al utrículo, con ayuda de la gravedad. Desde entonces, la terapia se basa en manipulaciones físicas, increíblemente útiles de forma inmediata. Pero hay formas atípicas resistentes al tratamiento estándar, algunas debidas a una afectación multicanal. Aunque varios estudios han comparado la efectividad de diferentes maniobras en cada tipo de VPPB, no está claro cuál es la mejor y tampoco sabemos qué estrategia seguir si la maniobra inicial no es útil, ¿se reitera la misma o se realiza otra? y si se aplica la misma, ¿cuántas veces se repite?

Con la búsqueda de respuestas debemos también asumir el impacto y los costes derivados de esta patología que dependen de su alta incidencia y tasa de recurrencia, del mayor riesgo de caídas que sufren sobre todo los pacientes mayores y del impedimento que supone para la actividad cotidiana.

Nos enfrentamos por tanto a un síndrome complejo, con una gran variedad de formas clínicas que pueden entremezclarse, con aspectos especulativos y controvertidos, cuya incidencia y grado de afectación social son importantes y donde el uso de una guía que sirva de orientación para el diagnóstico y tratamiento de este complicado proceso, será sin duda de gran ayuda en nuestro quehacer como especialistas, favoreciendo además la intervención protocolizada, que nos puede desvelar respuestas a tantos interrogantes.

Con estos propósitos se forja la Guía práctica del vértigo posicional paroxístico que os presentamos. Basada en la sencillez, partimos con una introducción general donde se incluye la forma de explorar al paciente, explicando a continuación, la manera de diagnosticar y tratar mediante diferentes maniobras, la patología de cada conducto semicircular, con alguna pincelada particular y resaltando en forma de «avisos» lo que pueden ser áreas de conflicto o de especial interés. Pero la simplicidad no impide que podamos llegar a plantear esos temas controvertidos, frontera con lo desconocido y de candente actualidad, como el VPPB multicanal, el atípico y central, el subjetivo o el del anciano; para terminar finalmente, con un capítulo dedicado al seguimiento y a la forma de enfrentarnos con las recurrencias. En definitiva, lo que pretende la Guía práctica del vértigo posicional paroxístico es resultar útil a quienes tratan con esta patología.

Han sido muchos los especialistas de otorrinolaringología de la Sociedad Otorrinolaringológica de Castilla y León, Cantabria y La Rioja, que han decidido brindar su esfuerzo y pasión por la otoneurología, aportando conocimiento a estas páginas que presentamos. Sin ellos no hubiera sido posible. De hecho, consideramos que éste es el principal logro de la Guía práctica del vértigo posicional paroxístico: el trabajo en común, el apoyo mutuo, la comunicación entre profesionales, el vínculo en lo científico, y la obtención de un gran resultado que no es sino fruto de ese esfuerzo solidario. Esa es nuestra principal satisfacción.

Deseamos que esto no sea más que el comienzo de una carrera en común entre los diferentes miembros de la Sociedad Otorrinolaringológica de Castilla y León, Cantabria y La Rioja, que están interesados en los temas otoneurológicos.

Pero esta guía no habría tenido el colorido que presenta, sin la ayuda de nuestro querido amigo y colega en tierras extremeñas, el Dr. Gabriel Trinidad, cuyos espléndidos dibujos, reflejo de su capacidad artística y profundo conocimiento, facilitarán la comprensión de las distintas maniobras. Un abrazo.

Y nuestra gratitud a Revista ORL y a su director, Dr. José Luis Pardal, que han permitido que esta guía os llegue a vosotros, queridos lectores.

\section{BIBLIOGRAFÍA}

1. Báràny $R$. Diagnose von Krankheitserscheinungen im Bereiche des Otolithenapparates. Acta Otolaryngol (Stockh). 1921;2:434-7. 
GUÍA PRÁCTICA DEL VÉRTIGO POSICIONAL PAROXÍSTICO BENIGNO: LA COLABORACIÓN COMO CAMINO A LA MEJORA ASISTENCIAL BENITO-OREJAS JI Y BATUECAS-CALETRIOO A

2. Dix MR, Hallpike CS. The pathology, symptomatology and diagnosis of certain common diseases of vestibular system. Proc $\mathrm{R}$ Soc Med. 1952;78:987-1016.

3. Hall SF, Ruby RRF, McClure JA. The mechanics of benign paroxysmal vertigo. J Otolaryngol. 1979;8:151-8.
4. Schuknecht HF. Cupulolithiasis. Arch Otolaryngol. 1969;90:765-78.

5. Epley JM. The canalith repositioning procedure: For treatment of benign paroxysmal positional vertigo. Otolaryngol Head Neck Surg. 1992;107:399-404. 